\title{
Survey About Impact Voltage Instability and Transient Stability for a Power System with an Integrated Solar Combined Cycle Plant in Iraq by Using ETAP
}

\author{
Ahmed Z. Abass ${ }^{1 *}$, D.A Pavlyuchenko ${ }^{2}$, Zozan Saadallah Hussain ${ }^{3}$ \\ ${ }^{1,2}$ Novosibirsk State Technical University, Novosibirsk, Russia \\ ${ }^{3}$ Technical Institute, Northern Technical University, Mosul/ Iraq \\ ${ }^{1}$ theking.amir@mail.ru, ${ }^{2}$ pavlyuchenko@corp.nstu.ru, ${ }^{3}$ zozan.technic@ntu.edu.iq \\ *Corresponding Author
}

\begin{abstract}
The Analyses for power systems are more necessary for the designing, operating phase execution control and to make sure safe network operations by sufficient protection project settings. In this article, we have prepared a sufficient scientific survey about the electrical model of a 340 MW integrated solar combined cycle system (ISCCS) located in the Iraqi southern, is developed and simulation by a program called Electrical Transient Analyzer Program (ETAP) and carry out throw this program the load flow, voltage stability and short circuit analyses for this power plant with part of the national grid in Al-Basra city in an industrial region. The effect of voltage instability for the grid on system buses (load buses) of the power system is estimated. By using load flow analysis as a case study by using the Newton-Raphson algorithm, when the load buses operating at down voltage because of instability voltage of the power grid are specified and their voltages are should to improved according to given voltage limitations that are depended on buses criticality with regard to loads. The appliance on-load tap changers of the transformer and reactive power compensation are used to improve steady-state voltage stability for any instability system. The method of the optimal position for capacitor banks placement is meaning the number of capacitor banks is proposed to adding to the weak buses by using the optimal capacitor placement module of ETAP. Energy is actually required for the expansion of our country. To sustain the generation of electric power at an adequate level power system supplies power to different types of loads that are located far away from the generating plants using transmission lines.
\end{abstract}

Keywords - load flow, ETAP, transient stability, optimal capacitor placement $(\mathrm{OCP})$.

\section{INTRODUCTION}

Power system is the network of electrical parts used to provide, transfer and employ electric power. This power system is called the grid that can be generally divided into the generators that supply the power by using different energy sources to, the transmission system that carries the power from the generating centers to the load centers and the distribution system that feeds the power to homes and industries. Actually that the unit of electric energy generated by power station does not correspond with the units distributed to the consumers. Some proportion of the units is lost during the transmission of power from generation to distribution network. This difference in the generated \& distributed units is known as transmission and distribution loss.

From 1980 and today, Iraq has been in an uninterrupted war and has crashed all the infrastructure. In 1980, when the Iran-Iraq warfare started, which continued for 8 years without interruption. In this war caused growing in government spending on the war and decreased spending on infrastructure, especially electricity sector. It is obvious the electrical power supply and generation have been running short of demand from 1991 after the gulf war [1-5]. While today, in 2020, Iraq still suffers from a severe shortage in the processing of electricity to citizens, and noting that more $80 \%$ of the factories and government buildings are still out of work.

The demand for electricity in Iraq growing from 11000 MW in 2007 to $16000 \mathrm{MW}$ in 2013, to $24500 \mathrm{MW}$ in summer 2018, and is expected that this demand will be increased to more than $30000 \mathrm{MW}$ in 2022. About $70 \%$ of the total electricity produced in 2013 was lost, which includes both technical, commercial and administrative losses (Transmission-6\%, Distribution-13\%; theft and non-billed23\%; Non Collected 26\%; and collected 33\%). Over $90 \%$ of the losses are in the distribution network of which $79 \%$ are losses not technical (theft or not billed and not collected energy) [5-11].

The distribution system generally is in very bad situation and appears to be one of the narrowness in the electricity supply, as it is deformed by incompetent administration and shortage of investment. The ultimate and unplanned growth, in addition to the aging of the electric network, have led to overloading and strongly suffering from many high (technical and not technical) losses. For example, distribution lines that carry limited quantities of power over short distances are a major contributor to system losses.

Total transmission and distribution losses account for about $40-50 \%$ of the system losses in Iraq, with the majority of this loss due to the distribution sector (i.e., $80-90 \%$ of the total transmission and distribution losses). Inefficient management and operation of the distribution sector are contributors to this issue, including billing, metering, 
customer service, and an inability to increase system performance.

The use of modern technology and advance planning has a great direct impact in reducing losses. In this paper we show that the absence of planning is one of the main causes of electrical energy losses. The load flow, stability of voltage and short circuit analyses are always wanted for right installation, constant \& efficient operation, and protective schema settings of power system. These detailed analyses give data input of the system that might be are needed for future expansion and enhancement in the system.

The load flow analysis is a mathematical way utilized by electrical engineers for future planning and defining several load buses, their phase angles, real and reactive power passing from all system elements under normal steady operation [12-16]. The voltage stability of a power system is its ability to safe constant voltages at all buses when any troubles changes the given operating conditions. It depends on its ability to maintain a correspond between load request and equipping from the power system. The under voltage produced by the power grid instability has negative effect on distribution system. Instability leads to a slow rise or fall in voltages at some buses. This results in tumble of loads, transmission lines and other system elements due to a many of outages, may be some generators lose synchronism by these outages [16-19].

\section{DESCRIPTION OF POWER PLANT}

In this paper, we report on simulation of the electrical system of a $340 \mathrm{MW}$ type ISCCS by ETAP and the analysis of load flow. Then, under voltage state of load buses are fixed and their voltages are improved according to wanted pre-set voltage range, by the on load tap changer regulation and the optimal capacitor placement method. Electrical system of a 340 MW ISCC having four gas turbines and two steam turbines [1]. Four gas turbine generators (50 MW) and steam turbine generators (65 MW and $75 \mathrm{MW}$ ) are connected to main bus (Khur Zubair) each generator is connected to the central bus by its step-up transformer and are producing power at $20 \mathrm{kV}$ voltage, then transformed to $132 \mathrm{kV}$ [4].

Then step-up transformers upgrade voltage to $400 \mathrm{kV}$ to add this power to national grid throw two 3-winding transformers with 250 MVA. Khur Zubair bus feeding 8 main loads (steel factory 22MW, Fao 21.6 MW, bab Zubair 20.5MW, Rumaila field 80MW, um qaser city and port 220MW, Zubair field 45MW, Albaker port 20MW, center city $110 \mathrm{MW}$ ) most of the loads are consumed in the oil fields, factories and ports, as the deficit is covered by the national grid. We have carry out this study about section of grid on ETAP and then performed all required analyses, look at Fig.1

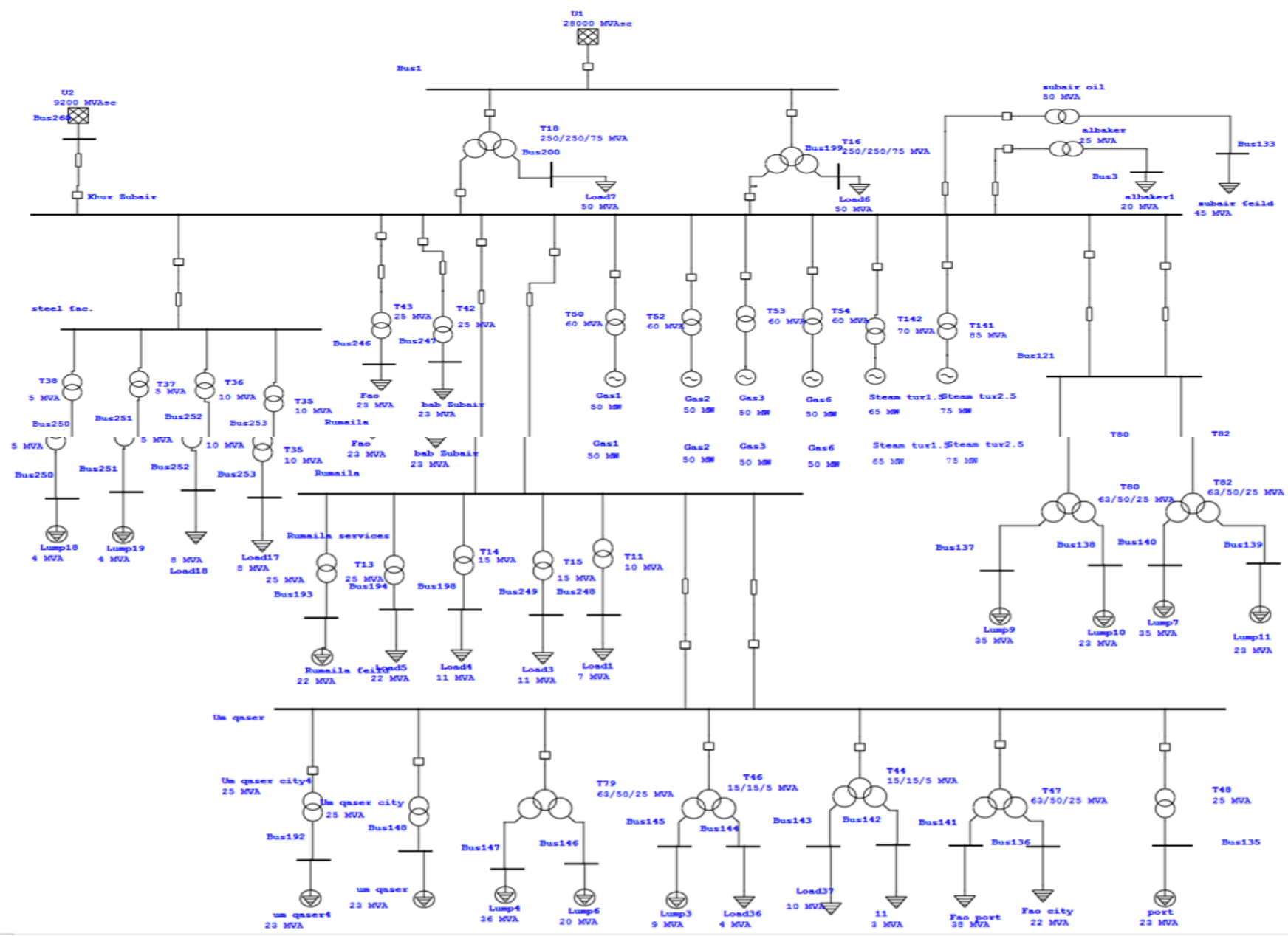

Fig. 1. One-line diagram of $340 \mathrm{MW}$ power plant 


\section{ANALYSIS OF LOAD FLOW}

The load flow analysis for any system is mathematical method used for find out system elements for any electrical system in normal steady operation, so that helpful in planning and operation for power system. For carry out load flow analysis we need to calculate the admittance $\mathrm{Y}_{\text {bus. }}$ The nodal equations for a power system network using $\mathrm{Y}_{\text {bus }}$ can be written as follows with main equations [5,20-29].

$$
\begin{gathered}
\mathrm{I}=\mathrm{Y}_{\text {bus }} * \mathrm{~V} \\
\mathrm{I}_{\mathrm{i}}=\sum_{j=1}^{n} \mathrm{Y}_{\mathrm{ij}} * \mathrm{~V}_{\mathrm{j}} \quad \text { где } \mathrm{i}=1,2,3, \ldots \mathrm{n} \\
\mathrm{P}_{\mathrm{i}}+\mathrm{jQ}_{\mathrm{i}}=\mathrm{V}_{\mathrm{i}} \mathrm{I}_{\mathrm{i}}{ }^{*} \\
\mathrm{I}_{\mathrm{i}}=\left(\mathrm{P}_{\mathrm{i}-\mathrm{j}} \mathrm{j}_{\mathrm{i}}\right) / \mathrm{V}_{\mathrm{i}}^{*} \\
\frac{P i-j Q i}{V i^{*}}=V_{i} \sum_{j=1}^{n} Y i j-\sum_{j=1}^{n} Y i j V j \quad j \neq i
\end{gathered}
$$

Where $P_{i}$ and $Q_{i}$ (real and reactive) power for bus $i$.

Several load flow ways are take on to analyze steady state for any electrical system. In this paper and by using program ETAP we have selected the method (Newton-Raphson) technique and algorithm because it is the faster way and needs minimal number of iterations when compared to other techniques and its reliability is relatively good [30-36].

\section{A. Newton-Raphson Method}

To implement this method, we need to analyze the main equations and substitute them together to get the final result, through which the program performs the calculations of the load flow, for example by expressing equation (2) putting it into equation (3) the real and imaginary components of equation will be:

$$
\begin{aligned}
& P_{i}=\sum_{j=1}^{n}|V i||V j||Y i j| \cos (\theta i j-\delta i+\delta j) \\
& Q_{i}=\sum_{j=1}^{n}|V i||V j||Y i j| \sin (\theta i j-\delta i+\delta j)
\end{aligned}
$$

Where $\delta_{\mathrm{i}}, \delta_{\mathrm{j}}$ and $\theta_{\mathrm{ij}}$ are angles of $\mathrm{V}_{\mathrm{i}}, \mathrm{V}_{\mathrm{j}}$ and $\mathrm{Y}_{\mathrm{ij}}$. And equ. (6) and (7) expanded in Taylors series about the initial estimate, neglecting all higher order terms, and writing it in matrix form [6-8].

$$
\left[\begin{array}{l}
\Delta P \\
\Delta Q
\end{array}\right]=\left[\begin{array}{ll}
J_{1} & J_{3} \\
J_{2} & J_{4}
\end{array}\right]\left[\begin{array}{c}
\Delta \delta \\
\Delta|V|
\end{array}\right]
$$

$J_{1}$ to $J_{4}$ are the entries of the Jacobian matrix. The diagonal and the off-diagonal elements of $J_{l}$ are

$$
\begin{gathered}
\frac{\partial P i}{\partial \delta i}=\sum_{j \neq 1}|V i||V j||Y i j| \cos (\theta i j-\delta i+\delta j) \\
\frac{\partial P i}{\partial \delta i}=-|V i||V j||Y i j| \sin (\theta i j-\delta i+\delta j)
\end{gathered}
$$

The difference between the schedule and calculated values known as power residuals for the terms $\Delta P_{i}{ }^{(k)}$ and $\Delta Q_{i}{ }^{(k)}$ is as:

$$
\begin{aligned}
& \Delta P_{i}^{(k)}=\Delta P_{i}^{s c h}-P_{i}^{(k)} \\
& \Delta Q_{i}^{(k)}=\Delta Q_{i}^{s c h}-Q_{i}^{(k)}
\end{aligned}
$$

New estimates for bus voltage are:

$$
\begin{gathered}
\delta^{(k+1)}=\delta_{i}^{(k)}+\Delta \delta_{i}^{(k)} \\
\left|V^{k+1}\right|=\left|V_{i}^{(k)}\right| \Delta\left|V_{i}^{(k)}\right|
\end{gathered}
$$

\section{LOAD FLOW ANALYSIS AND ITS RESULTS}

Checking of the system performance i.e., testing of the efficiency of all system element ratings, transformer sizes and their impedances and tap changer settings under a difference of operating conditions including emergency conditions. The major objective of the load flow analysis is definition of the steady state active and reactive power flows, current flows, system power factor and system voltage profiles (magnitudes and phase angles of load and generator bus voltage). Fig. 2 shows the load flow analysis results of the system.

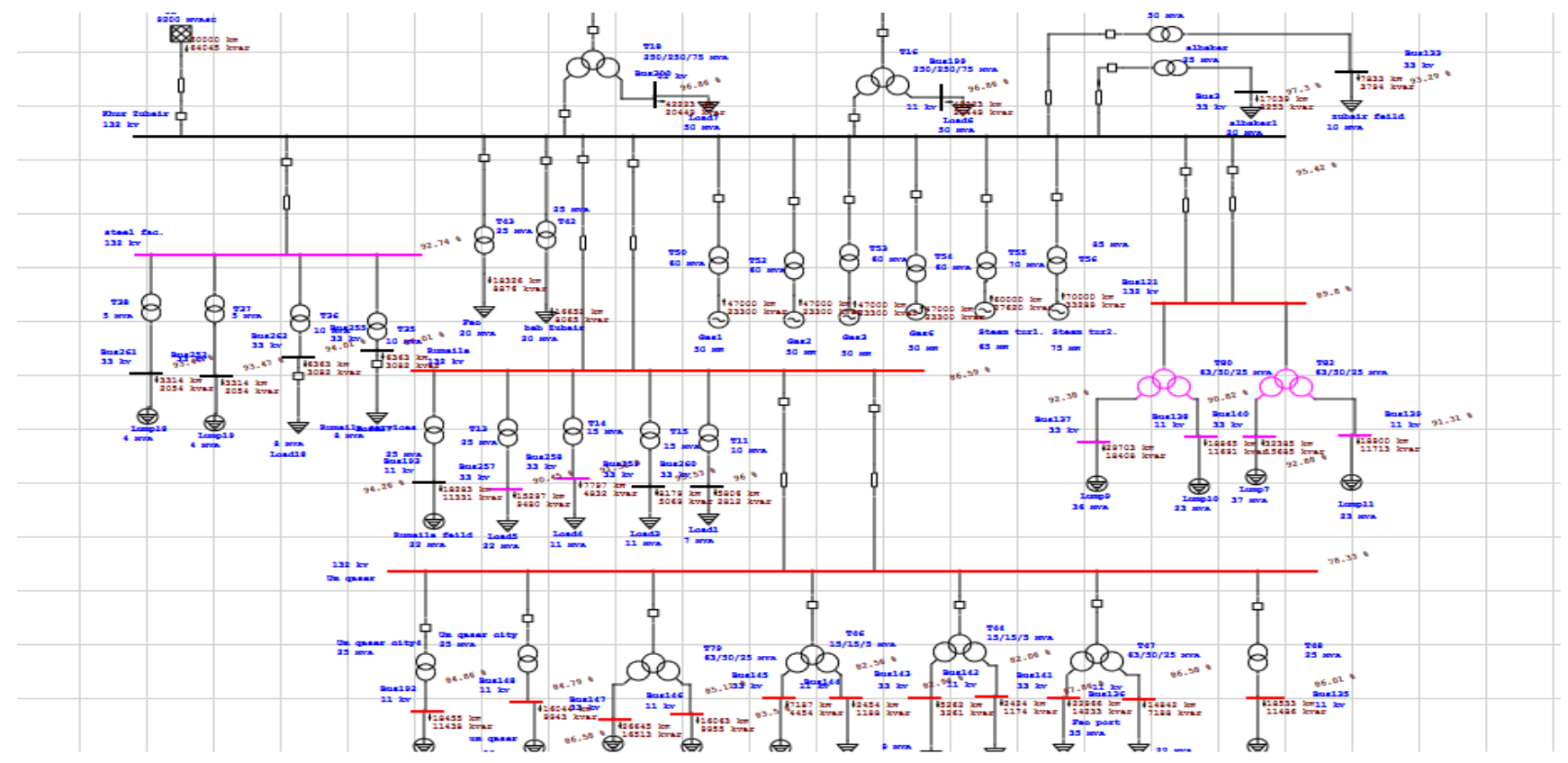

Fig.2. Single diagram for load flow of system

Ahmed Z. Abass, Survey About Impact Voltage Instability and Transient Stability for a Power System with an Integrated Solar Combined Cycle Plant in Iraq by Using ETAP 
From this single diagram after carrying out load flow analysis using ETAP an alert summary report is generated which tells us which part of the system needs immediate attention and it can be clearly seen from the on line diagram that the um qaser and Bus 121 are operating at an under voltage and these buses contain many branches with nominal voltage $(11 \& 33 \mathrm{kV})$. After carrying out load flow we getting in Table 1 .

TABLE I. LOAD FLOW ANALYSES

\begin{tabular}{|c|c|c|c|c|c|c|c|c|c|}
\hline \multirow{2}{*}{$\begin{array}{l}\text { bus } \\
\text { ID }\end{array}$} & \multicolumn{3}{|c|}{ Voltage } & \multirow[t]{2}{*}{ No. Branches } & \multirow[t]{2}{*}{$\mathbf{k V}$} & \multicolumn{4}{|c|}{ Load flow } \\
\hline & $\mathbf{k V}$ & \%mag. & angle & & & MW & Mvar & amp & $\% \mathrm{pf}$ \\
\hline \multirow[t]{2}{*}{121} & 132 & 91.044 & -3.9 & $137 \& 138$ & $33 \& 11$ & 48.899 & 37.816 & 300.4 & 79.2 \\
\hline & & & & $139 \& 140$ & $11 \& 33$ & 51.624 & 35.270 & 304.5 & 82.7 \\
\hline \multirow[t]{11}{*}{ Umqaser } & 132 & 85.138 & -6.2 & Bus135 & 11 & 18.558 & 11.501 & 1326.5 & 85.3 \\
\hline & & & & Bus148 & 11 & 16.065 & 9.956 & 1165.0 & 85.4 \\
\hline & & & & Bus192 & 11 & 18.480 & 11.453 & 1338.9 & 85.6 \\
\hline & & & & Bus142 & 11 & 2.442 & 1.183 & 172.9 & 90 \\
\hline & & & & Bus 143 & 33 & 5.301 & 3.285 & 131 & 85 \\
\hline & & & & Bus144 & 11 & 2.474 & 1.198 & 174.0 & 90 \\
\hline & & & & Bus 145 & 33 & 7.196 & 4.459 & 176.6 & 85 \\
\hline & & & & Bus136 & 11 & 14.952 & 7.242 & 1003.5 & 90 \\
\hline & & & & Bus 141 & 33 & 23.137 & 14.339 & 540 & 85 \\
\hline & & & & Bus146 & 11 & 16.085 & 9.969 & 1161.8 & 85 \\
\hline & & & & Bus 147 & 33 & 26.682 & 16.536 & 631.6 & 85 \\
\hline
\end{tabular}

\section{TRANSIENT STABILITY ANALYSIS}

Definition of the system response due to different disturbances which are the source of instability i.e., which lead to loss of synchronism or stopping or overloading of generators and motors. Switching transients are mostly related with go wrong of circuit breakers and switches, switching of capacitor banks and other frequently switched loads [7-12]. In this paper we show the stability of system when it loses one of its loads (Rumaila field 22MVA) fig. 3 and fig. 4 shows the power angle of the system and speed of the generators respectively:

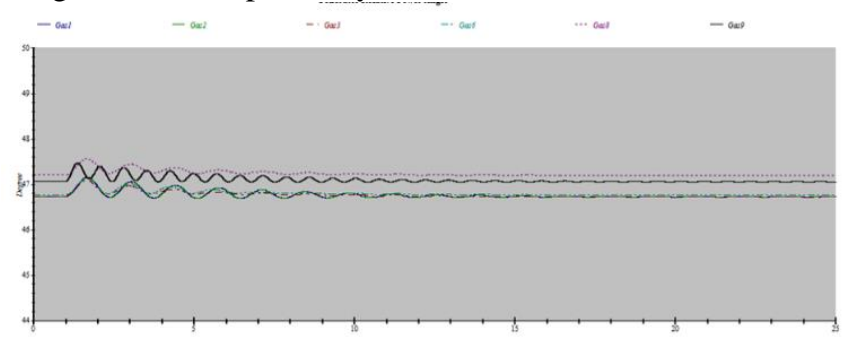

Fig. 3. power angle

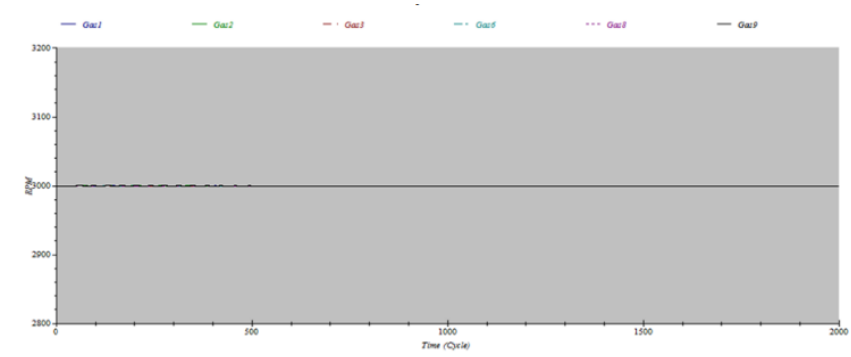

Fig. 4. speed of the generators

\section{VOLTAGE STABILITY ENHANCEMENT BY OCP}

From the mentioned table and single line diagram seen an under-voltage is included in power grid, due to this, voltage at system buses is reduced and to improve this voltage on load tap changers (OLTC) connected with transformers are employed. But as their range is only $\pm 10 \%$, voltage at some of load buses is still less than $95 \%$. So to enhance it moreover optimal capacitor placement (OCP) module of ETAP is employed. Input parameters are set for study case editor of OCP module. These include voltage constraints, candidate buses for voltage enhancement and ranking of capacitor banks. The voltage limitation is set to $95 \% \leq \mathrm{V} \leq 110 \%$ and it is global to all buses. ETAP is a fully graphical power systems analysis program. ETAP uses genetic algorithm technique for OCP. The objective of OCP is to minimize the cost of the system. These costs include four parts and can be represented mathematically as:

$\mathrm{M}_{\text {in }}$ objective function $=\sum_{i=1}^{N_{b u s}}\left(x_{i} C_{0 i}+Q_{c i} C_{1 i}+B_{i} C_{2 i} T\right)+$

$$
C_{2} \sum_{i=1}^{N_{l o a d}} T l P_{L}^{l}
$$

* Cost of fixed capacitor installation

* Cost of capacitor purchase

* Cost of capacitor bank operating (maintenance and depreciation)

* Real power losses cost

The results after operating OCP module are placed in Table 2 and Figure 5. The operating voltage values show that the voltage of both under voltage load buses is enhanced according to set voltage constraint [30-35]. The voltage ratings, sizes and number of capacitor banks for each undervoltage bus are also given. By comparing between figures and tables it can obviously be seen that the problem of an under 
voltage at all the buses is overcome by the placement of capacitor banks in shunt to the feeders.

TABLE II. RESULTS AFTER OCP.

\begin{tabular}{|l|l|l|l|l|l|l|l|}
\hline ID & Nom.kV & $\%$ mag & angle & $\%$ PF & No.banks & $\begin{array}{l}\text { Operated } \\
\text { kVAR }\end{array}$ & $\begin{array}{l}\text { Rated } \\
\text { kVAR }\end{array}$ \\
\hline 135 & 11 & 92.55 & -16.35 & 93.4 & 1 & 4281 & 5000 \\
\hline 136 & 11 & 91.695 & -17.47 & 93 & 1 & 4204 & 5000 \\
\hline 138 & 11 & 91.327 & -10.5 & 93 & 1 & - & 5000 \\
\hline 139 & 11 & 91.818 & -10.52 & 93 & 1 & - & 5000 \\
\hline 142 & 11 & 90.014 & -16.60 & 93 & 1 & 4051 & 5000 \\
\hline 144 & 11 & 92.528 & -17.64 & 93 & 1 & 4131 & 5000 \\
\hline 146 & 11 & 90.899 & -17.53 & 93 & 1 & 4280 & 5000 \\
\hline 148 & 11 & 91.066 & -15.34 & 93.8 & 1 & 4146 & 5000 \\
\hline 192 & 11 & 91.280 & -16.10 & 93 & 1 & 4195 & 5000 \\
\hline 193 & 11 & 96.269 & -10.25 & 90 & 1 & - & 5000 \\
\hline
\end{tabular}

TABLE III. COMPARING SYSTEM BEFORE AND AFTER OCP.

\begin{tabular}{|l|l|l|l|l|l|l|}
\hline ID & \multicolumn{5}{|l|}{ Before OCP } & After OCP \\
\hline No.шин & MW & $\mathbf{k V \%}$ & \%PF & MW & $\mathbf{k V \%}$ & \%PF \\
\hline 135 & 18.536 & 86.1 & 85 & 18.988 & 92.55 & 93.4 \\
\hline 136 & 14.952 & 86.6 & 90 & 16.66 & 91.695 & 93 \\
\hline 138 & 18.875 & 90.4 & 85 & 18.9 & 91.327 & 93 \\
\hline 139 & 18.911 & 91.3 & 85 & 18.95 & 91.818 & 93 \\
\hline 142 & 2.442 & 82.04 & 90 & 2.94 & 90.014 & 93 \\
\hline 144 & 2.474 & 82.6 & 90 & 3.08 & 92.528 & 93 \\
\hline 146 & 16.085 & 85.15 & 85 & 16.42 & 90.899 & 93 \\
\hline 148 & 16.065 & 84.8 & 85.4 & 16.42 & 91.066 & 93.8 \\
\hline 192 & 18.480 & 84.27 & 85.6 & 18.9 & 96.269 & 90 \\
\hline
\end{tabular}

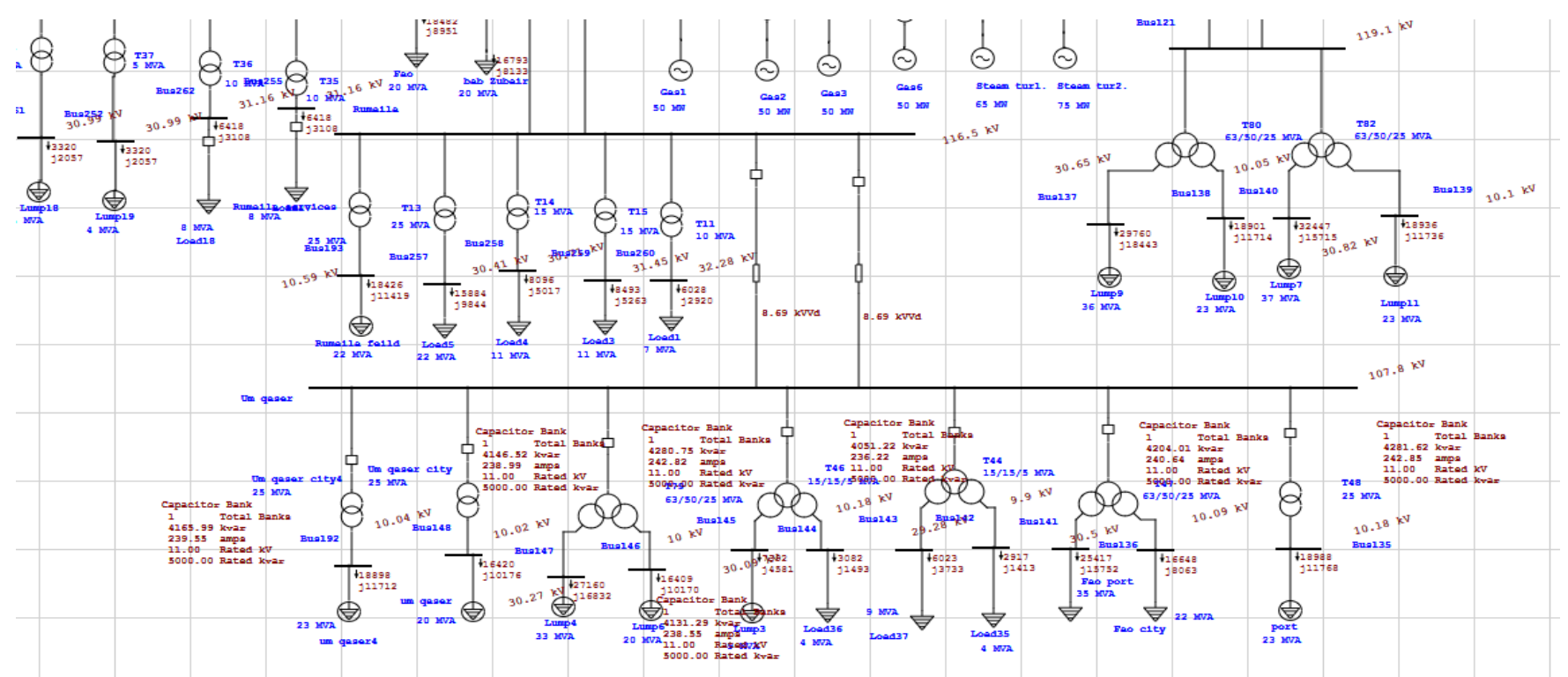

Fig. 5. Single diagram after OCP for system

\section{CONCLUSION}

In this paper load flow study using ETAP software is carried out with an approach to overcome the problem of an under voltage and power loses for electrical system of a ISCC located in south of Iraq with study of system stability. Load flow studies are significant for planning future expansion of power systems as well as in determining the best operation of existing systems. We discussed a station with part of the national network in southern Iraq, specifically Basra Governorate. Where it is considered an industrial and densely populated city, and the network suffers from continuous blackouts, major energy losses and major voltage disturbances resulting from several factors, the first of which is unexplored plans and the erratic distribution of energy. Through the program ETAP, we try to develop solutions to these problems, and through the OCP feature, weak branches 
were identified and a group of capacitors were added to compensate for the reactive power. It is clear from table 3 and figure 5 the impressive results obtained after the OCP procedure, which reflected positively on the whole system of improved voltage performance, reduced losses and improved power factor.

\section{REFERENCES}

[1] Abass Ahmed. Z., Pavlyuchenko.D.A ," Southern Iraq gas station conversation to integrated solar combined cycle", E3S web $\begin{array}{llll}\text { conferences } & 114 & 05008 & \text { (2019) }\end{array}$ https://doi.org/10.1051/e3sconf/201911405008.

[2] Abass Ahmed. Z., Pavlyuchenko.D.A ," Turning Iraq into a country of energy exporter through the exploitation of solar energy and vast desert land", E3S web conferences 114 ,05008 (2019) https://doi.org/10.1051/e3sconf/201911405008

[3] Abass Ahmed. Z., Pavlyuchenko.D.A ," The exploitation of western and southern deserts in Iraq for the production of solar energy" International Journal of Electrical and Computer Engineering (IJECE) Vol. 9, No. 6, December 2019, pp. 4617 4624 ISSN: 20888708, DOI: 10.11591/ijece.v9i6.pp4617-4624.

[4] Iraq, The Iraqi Ministry of Electricity, [Online]. Available: [https://moelc.gov.iq/]

[5] Kriti Singhal, "Comparison between Load Flow Analysis Methods in Power System using MATLAB", International Journal of Scientific \& Engineering Research, Volume 5, Issue 5, May 2014.

[6] Hadi Saadat, Power System Analysis, McGraw-Hill, 2006.

[7] Electrical Transient Analyzer Program (ETAP), www.etap.com

[8] Muhammad A.U, Qamar Saeed, Abdul R A, Arslan Qaiser," Load flow, voltage stability \& short circuit analyses and remedies for a 1240 MW combined cycle power plant using ETAP" Conference: 2017 International Conference on Innovations in Electrical Engineering and Computational Technologies (ICIEECT), DOI: 10.1109/ICIEECT.2017.7916568.

[9] Kanchana Baby, K. L. Sreekumar," Load Flow Analysis of 66 kV substation using ETAP Software" International Research Journal of Engineering and Technology (IRJET), vol. 04 no. 02, Feb -2017.

[10] Hasan F. Khazaal, Haider Th. Salim Alrikabi, Faisal Theyab Abed, Salah Ibrahim Kadhm," Water desalination and purification using desalination units powered by solar panels" Periodicals of Engineering and Natural Sciences, Vol 7, No 3 (2019). http://dx.doi.org/10.21533/pen.v7i3.748.

[11] Abass A.Z., Pavlyuchenko D.A., Balabanov A.M., Less V.M. Inclusion of solar energy in iraq gas-turbine power plants as a method of solving the country's energy system shortage. Power engineering: research, equipment, technology., vol. 22, no. 2, pp. 98-107. (In Russ.) https://doi.org/10.30724/1998-9903-2020-22-1-98-107.

[12] Ahmed Z. Abass 1, D.A Pavlyuchenko2, I.V. Kobobel3, solar energy perspectives in Iraq, Power engineering: research, equipment, technology. 2020 (45); pp 63-70.

[13] Rohit Kapahi, "Load Flow Analysis of $132 \mathrm{kV}$ substation using ETAP Software" International Journal of Scientific Engineering Research, vol. 4, issue 2, Feb 2013, pp. 1-5.

[14] Keith Brown, Herminio Abcede, Farookh Shokooh, Gary Donner "Interactive Simulation of Power Systems: ETAP applications and techniques", Page(s): 1930-1941, IEEE, 1990.

[15] P. M. Anderson and A. A. Fouad, "Power System Control and Stability". New York: IEEE Press, 1994.

[16] Push Raj (2013), Load Flow and Short Circuit Analysis of 400/220kv Substation, International Journal of Creative Research Thoughts, Volume1, Issue.4.

[17] TNGB ENGINEERS' ASSOCIATION 793, Anna Salai, Channai-600 002. (Tamil Nadu) 6th edition.

[18] William D. "Elements of Power System Analysis' 4th edition.

[19] Wu. Zhongxi and Zhou Xiaoxin, "Power System Analyses Software Package (PSASP)-an integrated powersystem analyses tool", ISBN: 0-7803-4754-4, Volume: 1, On page(s): 7-11 vol.1, 18-21 Aug 1998, Beijing, China.

[20] Glenn W. Stagg and Ahmed H. El-Abiad, "Computer Methods in Power System Analyses”, Bib ID 537411, New York, McGraw-Hill [1968], pp. 110-127.

[21] Annual Report, "Pakistan water and power development authority", 2006-2007.

[22] Gonen, T., "Electric Power Transmission System Engineering", Wiley, New York, 1986, pp. 87-93.
[23] R.A. Jabbar, Muhammad Akmal, M. Ali Masood, Muhammad Junaid and Fiaz Akram, "Voltage Waveform Distortion Measurement Caused by current drawn by Modern Induction Furnaces", Proceedings of $13^{\text {th }}$ ICHQP2008, IEEE, PES, ISBN: 978-1-42441771-1, 2008- 11-07 University of Wollongong, Australia.

[24] R.A. Jabbar, Muhammad Akmal, Muhamad Junaid and M.Ali Masood, "Operational and Economic Impacts of Distorted Current drawn by the Modern Induction Furnaces", Proceedings of AUPEC'08, IEEE, ISBN: 978-0- 7334-2715-2, 14-17 December, 2008, UNSW, Sydney, Australia.

[25] Sonwane, P.; Kushare, B. Optimal Capacitor Placement and Sizing: An Overview. International Journal of Innovative Research in Advanced Engineering (IJIRAE), 2014, 2.

[26] Carlisle, J.C.; El-Keib, A.A.; Boyd, D.; Nolan, K. A review of capacitor placement techniques on distribution feeders. In ssst; IEEE, 1997.

[27] Mitchell, M. Genetic algorithms: An overview. Complexity 1995, 1, 31-39.

[28] Chiang, H.-D.; Wang, J.-C; Cockings, O.; Shin, H.-D. Optimal capacitor placements in distribution systems. I. A new formulation and the overall problem. IEEE Trans Power Delivery 1990, 5, 634642.

[29] Baran, M.E.; Wu, F.F. Optimal capacitor placement on radial distribution systems. IEEE Trans Power Delivery 1989, 4,725-734.

[30] Eskandari Nasab, M.; Maleksaeedi, I.; Mohammadi, M.; Ghadimi, N. A new multiobjective allocator of capacitor banks and distributed generations using a new investigated differential evolution. Complexity 2014, 19, 40-54.

[31] AlHajri, M.; AlRashidi, M.; El-Hawary, M. A novel discrete particle swarm optimization algorithm for optimal capacitor placement and sizing. In: Canadian Conference on Electrical and Computer Engineering, CCECE 2007; IEEE, 2007.

[32] Mahmoodianfard, F.; Abyaneh, H.A.; Salehi, H.R.; Vahabzadeh, A.R. Optimal capacitor placement for loss reduction. In: 2010 Proceedings of the International Symposium Modern Electric Power Systems (MEPS); IEEE, 2010.

[33] Abdelaziz, A.; Ali, E.; Elazim, S.A. Flower pollination algorithm and loss sensitivity factors for optimal sizing and placement of capacitors in radial distribution systems. IntJ Electrical Power Energy Syst 2016, 78, 207-214.

[34] Ali, E.; Elazim, S.A.; Abdelaziz, A. Improved Harmony Algorithm and Power Loss Index for optimal locations and sizing of capacitors in radial distribution systems. Int J Electrical Power Energy Syst 2016, 80, 252-263.

[35] Ali, E.S.; Abd-Elazim, S.M. Stability improvement of multimachine power system via new coordinated design of PSSs and SVC. Complexity 2015, 21, 256-266.

[36] Mohammadi, M.; Ghadimi, N. Optimal location and optimized parameters for robust power system stabilizer using honeybee mating optimization. Complexity 2015, 21, 242-258. 